\begin{tabular}{|l|l|l|l|l|}
\hline Cuadernos de Investigación Geográfica & 2001 & N$^{\circ} 27$ & pp. 193-205 & ISSN 0211-6820 \\
\hline
\end{tabular}

(c) Universidad de La Rioja

\title{
THE EFFECT OF ATLANTIC AND PACIFIC SEA SURFACE TEMPERATURES ON THE MID-SUMMER DROUGHT OF COSTA RICA.
}

\author{
PETER WAYLEN ${ }^{(1)}$ \\ MARVIN QUESADA ${ }^{(2)}$
}

(1) Department of Geography, University of Florida, Gainesville, Florida, USA, 32611-7315.

(2) Departamento de Ciencias Sociales, Universidad de Costa Rica sede San Ramón, San Ramón, Alajuela, Costa Rica.

ABSTRACT: The mid-summer drought of Central America is an impor tant feature of the regional precipitation regime within the Pacific draina ge ranging from Mexico to Panama. The drought is less severe when the Atlantic is warmer. Cooler temperatures in the tropical Atlantic signify a strengthening of the North Atlantic anticyclone and the alisos. When com bined with warmer than usual temperatures (lower atmospheric pressures) in the eastern equatorial pacific, the pressure gradient across the isthmous increases and the orographic effects of the Cordillera are emphasized. When the Atlantic is warmer, the resultant reduction in the strength of the alisos reduces rainfall over most of the country.

RESUMEN: La sequía de mediados de verano en América Central es un fenómeno muy importante del régimen de precipitaciones desde Méjico a Panamá. La sequía es menos severa cuando el Atlántico está más cáli do. Temperaturas más frescas en el Atlántico tropical significan un refor zamiento del anticiclón nordatlántico y de los alisisos. Cuando se combi nan con temperaturas más cálidas (menor presión atmosférica) en el Pacífico ecuatorial oriental, el gradiente de presión a través del istmo aumenta, incrementándose el efecto orográfico de la Cordillera. Cuando el Atlántico está más cálido, la consiguiente reducción en la fuerza de los alisios reduce la precipitación en la mayor parte de la región.

Palabras clave: ENSO, Temperatura del mar, Lluvias tropicales, Alisios, Costa Rica. Key-words: ENSO, Sea temperature, Tropical rainfall, Alisos, Costa Rica.

\section{Introduction}

The mid-summer drought of Central America, known locally as the Veranillos de San Juan or Canicula, is an important feature of the regional precipitation regime within the Pacific drainage ranging from Mexico to Panama. Magaña et al. (1999) indicate that this abatement of summer (July-August) precipitation is unique in tropical climatology. The length and severity of the drought have important consequences for water resources- 
related activities including; agriculture, power generation and health. A reduction in the drought increases the risk of flooding in the subsequent months of heavy rains. George et al. (1998) also indicate a reciprocal relationship to rainfall and flooding within the Caribbean drainage of Costa Rica. Monthly precipitation and flood risks during this period in Costa Rica have been shown to be associated with the El Niño-Southern Oscillation (ENSO) phenomenon (Waylen et al., 1996; Waylen and Laporte, 1999), however that association is not as strong as has been found in many similar tropical regions (Ropelewski and Halpert, 1989). The recent renewed interest in the factors governing the variability of precipitation in Central America and the Caribbean (Enfield and Alfaro, 1999; Magaña et al.,1999; and Giannini et al., 2000), has furthered knowledge from earlier publications (Hastenrath, 1975; Ropelewski and Halpert, 1989; Waylen et al., 1996) and suggest that conditions of the tropical North Atlantic and Caribbean basin may be instrumental in modifying the response to ENSO. This paper investigates the nature and geographic extent of combined roles of sea surface temperature (SST) anomalies, in both the equatorial Pacific and North Atlantic Oceans, on the historic rainfall records of July and August at stations throughout Costa Rica.

Magaña et al. (1999) propose that an intensification of the trade winds over the Caribbean leads to divergent anomalies and inhibition of deep convection, over the warming waters off the Pacific coast of Central America. Giannini et al. (2000) examined the influence of sea level pressures and temperatures over the tropical North Atlantic and eastern Pacific (Niño3) on rainfall totals over the Caribbean basin. When a strong pressure gradient exists across the isthmus of Central America, the trade winds, or alisios, intensify, leading to a drier than average dry season over Costa Rica, which is particularly pronounced during the mature phase of ENSO. Enfield and Alfaro (1999) also sought links between atmosphere/ocean conditions in the two ocean basins, suggesting that this may be a contributing factor to the unclear association between ENSO and precipitation in the region (Ropelewski and Halpert, 1989). They conclude that the greatest effect of SST can be identified in the dates of onset and conclusion of the rainy season in southern Central America (Costa Rica and Panama), a result supported by an analysis of flooding in four rivers along the Pacific slope of Costa Rica (Waylen and Laporte, 1999). However, due to the limited sets of daily precipitation data, and the use of data derived from $2.5 \infty$ grid squares, the results of Enfield and Alfaro (1999) and Giannini et al. (2000) lacked a geographic resolution appropriate to the mountainous topography of the area.

\section{Data}

Monthly precipitation data for Costa Rica were obtained from Instituto Metereológico Nacional (Ministerio de Recursos Naturales, Energia y Minas, 1988) and have been updated from various sources since. SST anomalies 1950-1999, in both the tropical North Atlantic $\left(5-20^{\circ} \mathrm{N}, 30-60^{\circ} \mathrm{W}\right)$ and Niño3.4 $\left(5^{\circ} \mathrm{N}-5^{\circ} \mathrm{S}, 120-170^{\circ} \mathrm{W}\right)$, shown in figure 1, were obtained from NOAA at www.nnic.noaa.gov/data/indices/index.html. Only meteorological records possessing at least 20 years of complete summer monthly records during the period 1950-1999 are employed in the subsequent analysis. Figure 1 

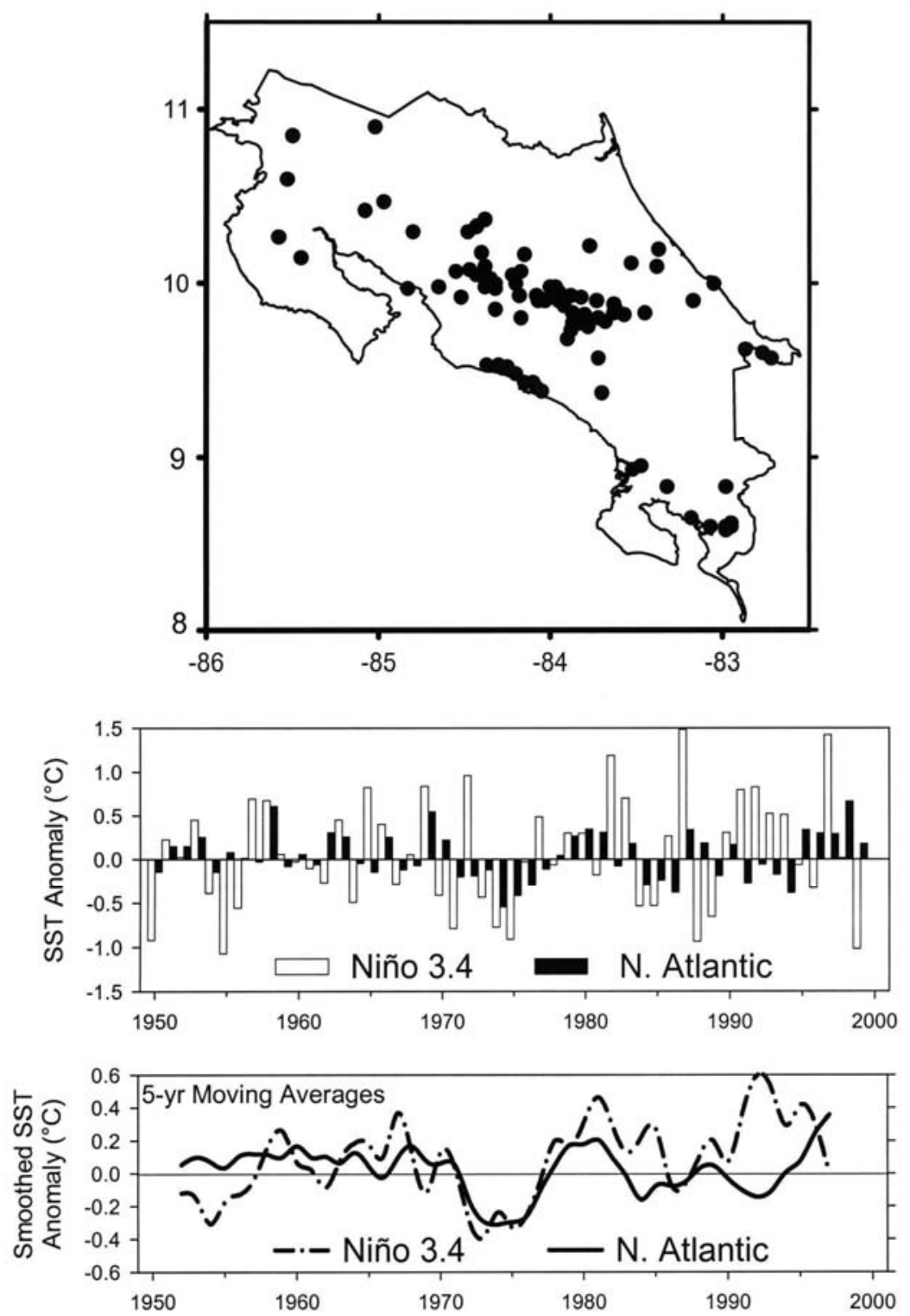

Figure 1. Locations of meteorological stations employed in the study (upper) and raw and smoothed time series of the sea surface temperature anomalies in the Niño34 region of the Pacific Ocean and the tropical North Atlantic, 1950-1999 (lower).

reveals stations in all regions of Costa Rica, with the exception of the extreme northeast and east central regions, and a strong bias towards the populated Central Valley. Following the definition of the Veranillos and Caniculas in this region (Hastenrath, 1967, 
1975; George et al., 1998, and Magaña et al., 1999), July and August rainfalls are summed to create a single seasonal total. For the sake of simplicity and to maximize the size of the available data sets, each set is subdivided into four categories dependent upon the SST anomalies (positive or negative) in the two oceans in the corresponding season.

\section{Analysis}

Statistical comparisons of the medians of seasonal totals under each combination of warm/cool ocean temperatures are carried out by means of a one-tailed Mann-Whitney test. This test is employed in preference to a t-test as it requires no distributional assumptions about the data. Given the tremendous spatial variability in both the mean and standard deviation of monthly and seasonal rainfall (Waylen et al., 1996), the assumption of normality is unlikely to hold, particularly in the drier northwest. Two one-tailed tests (medians greater than, and medians less than) are carried out at each station to determine whether one combination is wetter or drier than the other. Results of the tests are reported at the 0.05 level of significance. Given the four sets of combined oceanic conditions, six statistical inter-condition comparisons are possible. Because of the varying periods of the precipitation records, the number of observations in each sub-set based upon oceanic conditions is likely to vary from station to station. When the combined sample sizes of the two sub-sets being compared exceeds 10, the normal approximation may be employed in the calculation of the test statistic (Burt and Barber, 1996), otherwise the sampling distribution is available in specialized texts such as Conover (1980). In over $99 \%$ of the cases the normal approximation is applicable.

In this way the proportion of the 130 precipitation stations reporting significant changes (wetter or drier) in precipitation can be calculated. If the seasonal precipitation totals throughout Costa Rica are independent of the interaction of SST anomalies in the two oceans, the proportion of stations reporting significant changes between any combination of conditions involving a "cool" and a "warm" Pacific should remain the same regardless of the simultaneous condition of the Atlantic, and vice-versa. The proportions of stations reporting significant changes under a single oceanic condition (i.e., warm vs cool Atlantic, and warm vs cool Pacific) can be empirically calculated and viewed as the "marginal distributions " to which the proportions under the appropriate "bivariate" comparisons can be made statistically using a test of proportions. Figure 2 schematically represents the six possible combinations of conditions and the "oceanic marginals". The two comparisons involving opposing conditions in both oceans should yield proportions which are the cross-products of the two "oceanic marginals" under the null hypothesis of independence of seasonal rainfall from the interactive effects of SST anomalies in the two oceans.

Such comparisons are directly possible because the z-statistic used in the MannWhitney test is independent of sample size. The total number of stations reporting results from each comparison is always the same therefore sample sizes are not an issue in comparing the results of the tests of proportions.

In order to ensure that any patterns of change are the result of the interaction seasonal precipitation with ocean temperatures rather than the co-variation of sea surface tem- 


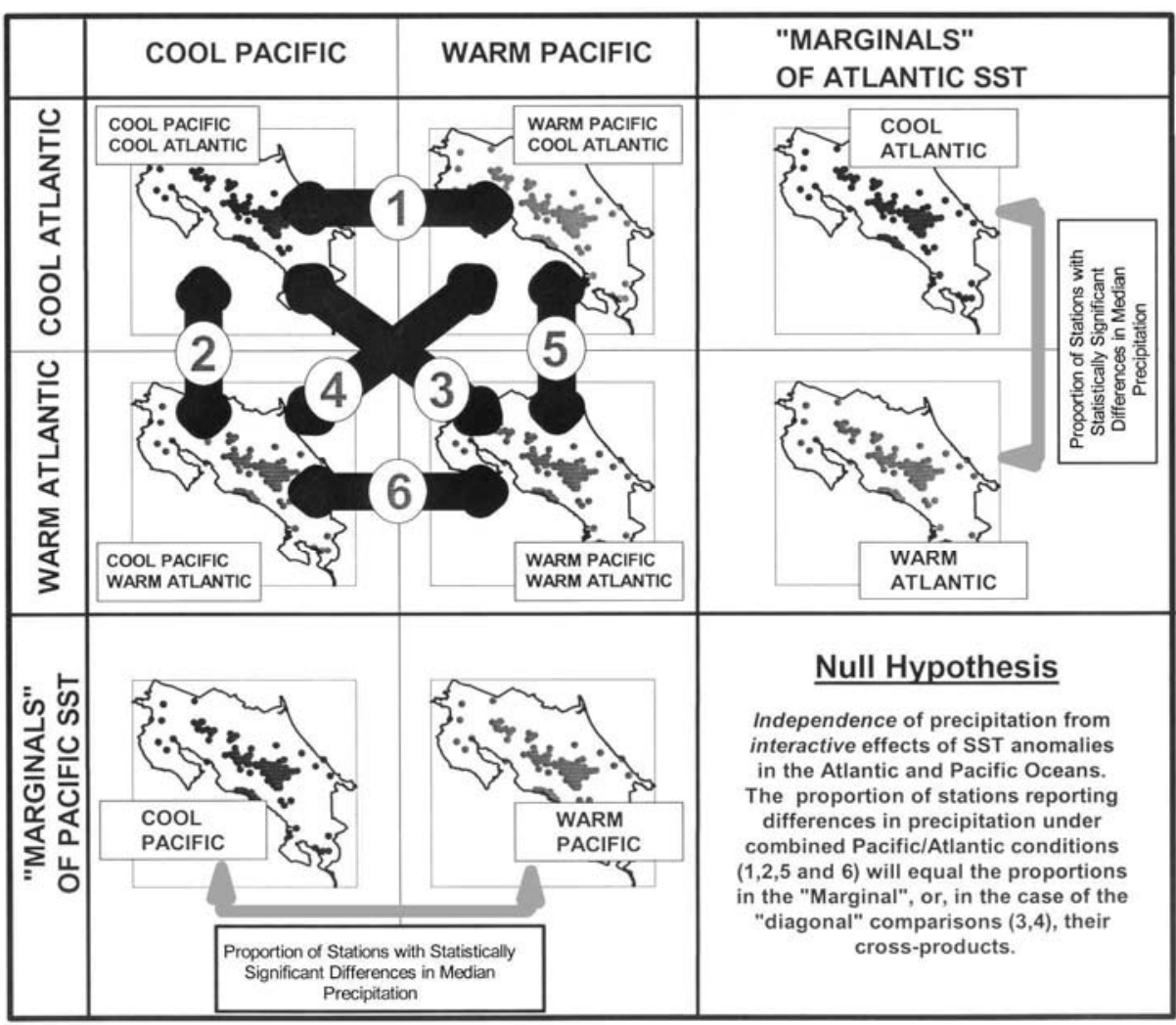

Figure 2. Conceptual framework employed in the research indicating the combinations of SST ano malies, their comparisons and conditions which constitute the null hypotheses of independence.

peratures in the two oceans, it must be shown that SSTanomalies can be viewed as being statistically independent of each other. Enfield and Alfaro (1999) report insufficient evidence to support dependence, however the results of more recent modeling work by Latif (2001) suggest a lagged relationship between the two. Employing only those sea surface temperature data for the period under study there is no significant correlation ( 0.05 level) between sea surface temperature anomalies in the two oceanic regions, aggregated to the seasonal or annual level (Figure 3). A lag-cross correlation analysis of annual anomalies does reveal significant positive values at lags -13 (north Atlantic preceding Pacific) and +1 (North Atlantic following Pacific), however all comparisons and combinations in this paper are carried out at lag 0 .

\section{Results}

Differences in seasonal precipitation between warm and cool years (Figure 4) are expressed as interpolated maps, in absolute terms and as a standard deviate from the long run mean conditions, and as sites at which the null hypothesis may be rejected. The pat- 
(a)

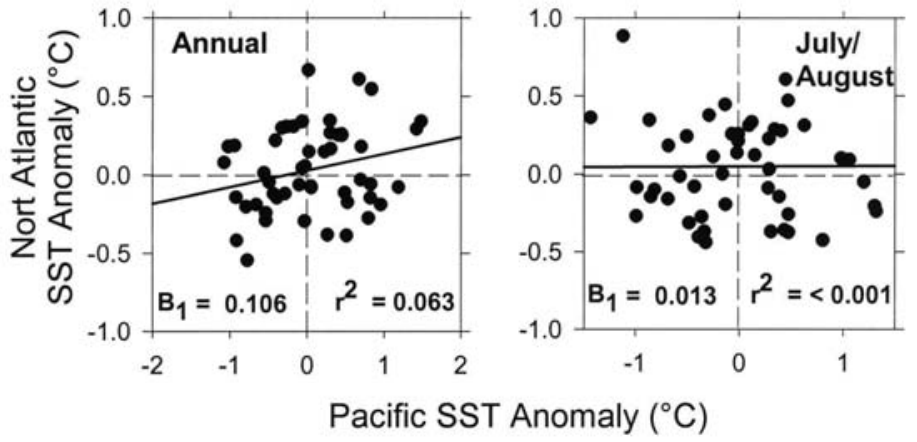

(c)

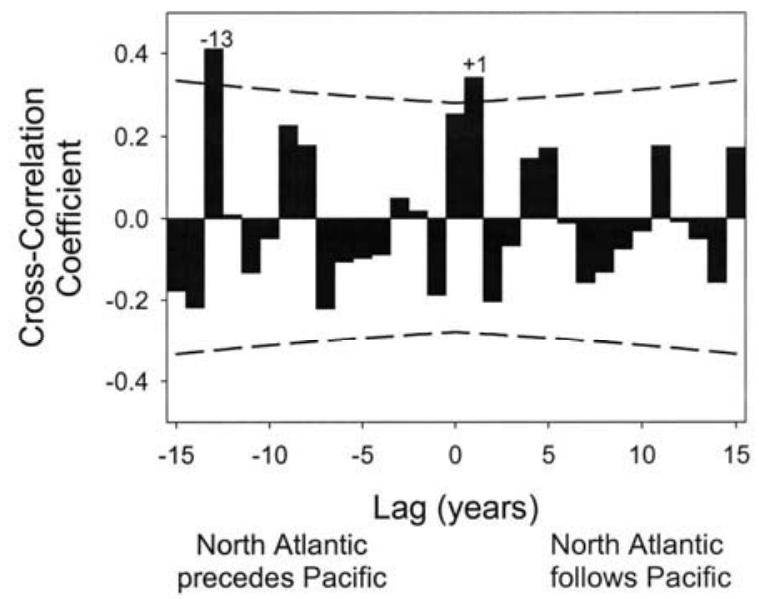

Figure 3. Simultaneous cross correlations between (a) annual SST anomalies and (b) SST ano malies averaged over July and August, and (c) the results of lag cross correlations between annual anomalies. Dotted line represents the $95 \%$ confidence limits.

terns resulting from comparisons between a cool and warm Pacific reflect those previously detailed (Waylen et al., 1996) with regard to La Niña and El Niño conditions. Although, the correspondence between positive (negative) temperature anomalies in the Niño3.4 region, as defined in this study, and El Niño (La Niña) events is not perfect, the association is apparent. A cool (warm) Pacific induces more (less) rain on the Pacific side of the Cordillera and less (more)on the Caribbean slope. Such changes may be of an order of greater than $+/-100 \mathrm{~mm}$ or one standard deviation from the long run mean. Forty-nine percent of the stations report significant changes. Of these, the vast majority $(42 \%)$ are wetter (drier) in years of a cool (warm) Pacific and are located along the Pacific slope. The number of significant results is smaller along the Caribbean slope, although it should 
(a)

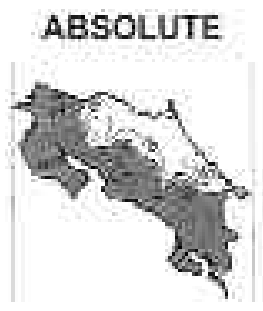

(b)

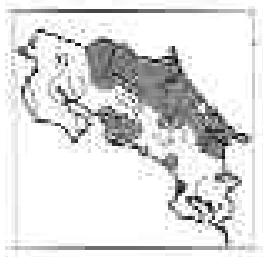

STANDARDIZED
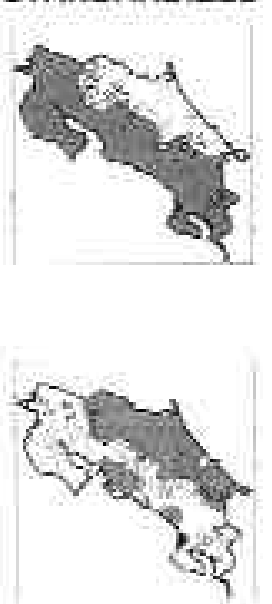

MANN-WHITNEY
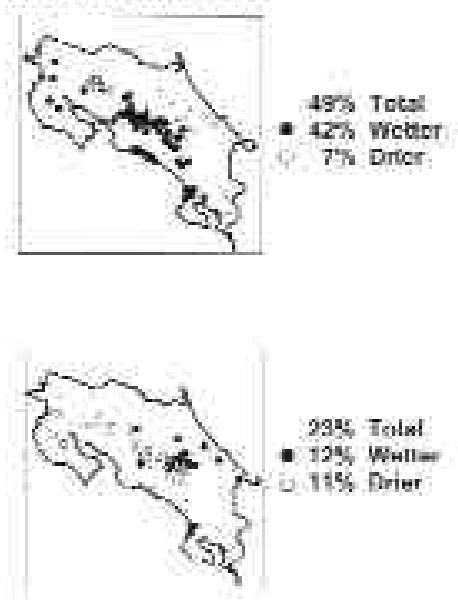

Figure 4. Measures of differences in seasonal precipitation totals observed in all years of cool oceanic conditions minus those observed under warm oceanic conditions for (a) the Pacific and (b) the Atlantic. Maps to the left express absolute differences in mean seasonal precipitation $(\mathrm{mm})$, those in the center express the same difference but as standard normal deviates based on the long-run mean and variance at each station, those of the right indicate stations at which the Mann-Whitney test reveals significant differences in medians.

be noted that there are fewer recording stations in this area. Twenty-three percent of all stations report significant changes conditioned solely upon temperatures in the North Atlantic. These are more evenly divided between wetter and drier responses. Geographically, the stations are more restricted to a central belt from the southern Caribbean coast (wetter when the Atlantic is cool) to Guanacaste in the northwest (drier when the Atlantic is cool). Stations located in and around the upper reaches of the Río Reventazón seem to be particularly sensitive to temperature anomalies in the Atlantic.

Figure 5 expresses mean seasonal rainfall under each of the four combined sets of SST anomalies. When the SST anomalies in each ocean are of differing signs, the deviations of seasonal rainfall on opposing flanks of the country appear to increase, and the geographic divide becomes clearer, particularly when a warm Pacific coincides with a cool Atlantic. When the anomalies are of the same sign the signal becomes effaced and, in the case of the warm Pacific, the topographic control of the cordillera seems to be removed resulting in normal or slightly below average rainfall through the country. This figure indicates that the response to a warm Pacific ( El Niño), in particular, is strongly conditioned upon the prevailing anomaly in the North Atlantic. There appears to be a similar, but somewhat muted, association during years of a cool Pacific ( $\sim$ La Niña). Thus, for instance, the drought along the Pacific slope, associated with a warm Pacific, drops from standard deviates of -0.75 or -1.00 when the Atlantic is cool to values of -0.25 or -0.50 when the Atlantic is warm. 


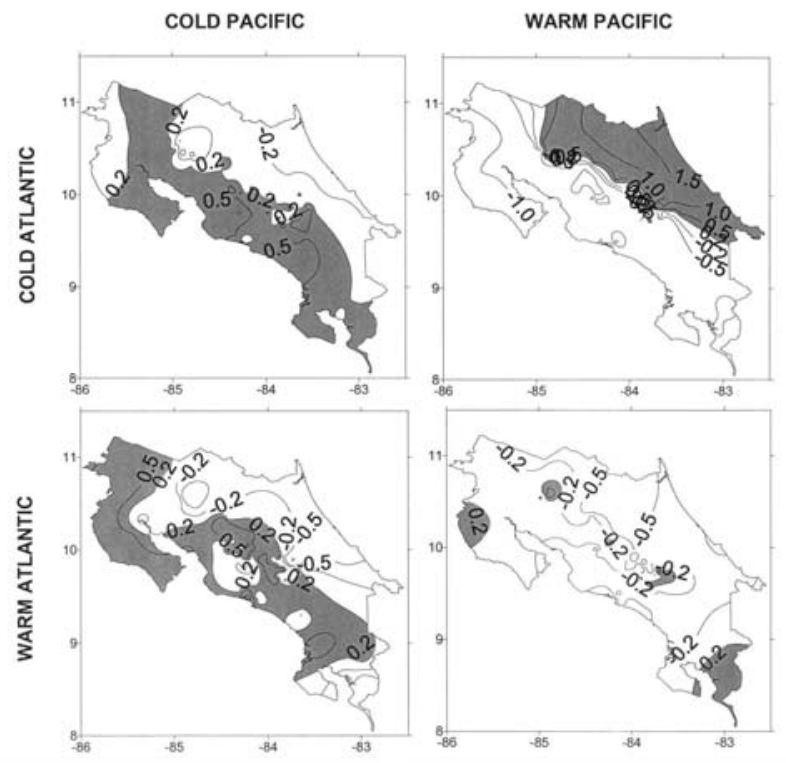

Figure 5. Mean seasonal precipitation totals under the four sets of sea surface temperature ano malies. All observations are expressed as standard normal deviates using the long run seasonal mean and variance at each station.

Although figure 5 gives an impression of the regional strength of response in seasonal rainfall to the SST anomalies, it may be misleading in those areas where data coverage is sparse or absent, particularly in the northeast. Figure identifies stations reporting statistically significant changes in seasonal rainfall between various pairs of SST anomalies. Whenever the pair of conditions shown along the horizontal axis of the diagram produces greater (less) seasonal rainfall than the paired conditions on the vertical axis, conditions are defined as "wetter" ("drier"). Considerable variation in the number and spatial disposition of stations reporting significant changes in rainfall can be observed.

Comparisons 1 and 6 show the differences in rainfall between a cool ( La Niña) and warm (El Niño) Pacific. Comparison 1 indicates those differences while the Atlantic is cooler and comparison 6 while it is warmer. In the absence of any interactive effect the proportions of stations reporting statistically significant differences should be the same and not significantly different from the proportion indicated in the upper portion of figure 4. Comparisons 2 and 5 indicate the locations of significant differences in rainfall between periods of a cool and warm Atlantic, conditioned upon a cool ( La Niña) and warm (El Niño) Pacific respectively. Under conditions of the null hypothesis these proportions should equal those depicted in the lower portion of figure 4. Comparison 3 contrasts rainfalls when both oceans experience the same anomalies, and comparison 4 contrasts rainfall when both oceans experience opposing anomalies. 


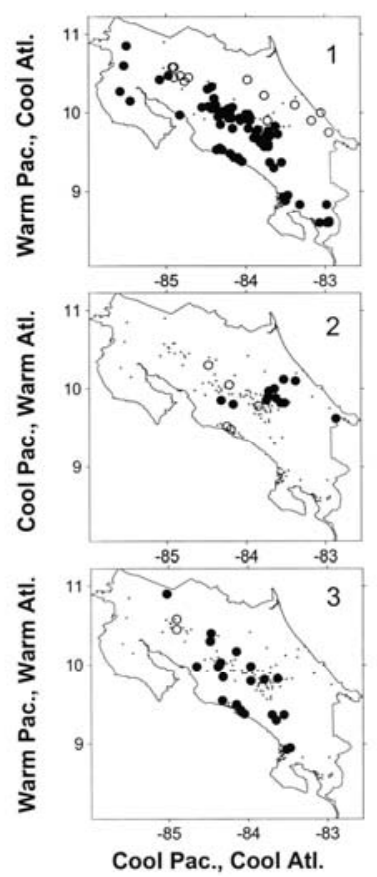

\section{COMPARISON OF JULYIAUGUST SEASONAL PRECIPITATION}

Seasonal precipitation, for conditions along vertical axis, are compared to seasonal figures for conditions along the horizont
statististically significant differences are plotted.

Horizontal Condition > Vertical Condition : Wet Horizontal Condition < Vertical Condition : Dry

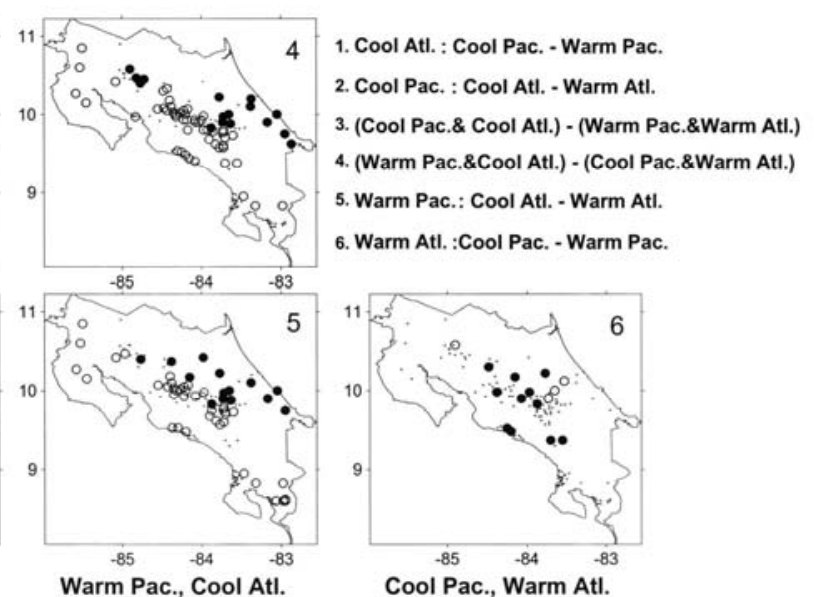

Figure 6. Stations reporting significant changes in median seasonal rainfall totals under the six possible comparisons of paired combinations of SSTanomalies.

The first six lines of figure 7 summarize the results of the tests of proportions applied to each of the six comparisons and their appropriate "marginal" or "cross-product". Line 1 indicates that a significantly larger proportion of stations undergo changes in precipitation in response to temperature fluctuations in the Pacific, if the Atlantic is cold. The greater response is found in stations reporting more rainfall. By contrast, a similar comparison (line 6) reveals a significant reduction in the proportion of stations experiencing significant shifts in rainfall if the Atlantic is warm. Reductions in the proportions of stations reporting either wetter or drier conditions are significant.

The number of stations reporting significant differences in seasonal rainfall between years of negative and positive anomalies in North Atlantic SSTs (Figure 4) was fairly low (23\%). Line 2 of figure 7 shows that there is a significant reduction in this proportion when the comparison is conditioned upon a cool ( La Niña) Pacific. In particular, the proportion of stations normally reporting wetter conditions during a cool Atlantic has declined. The proportion of stations reporting significant reductions in rainfall during periods of cooler north Atlantic SSTs increases significantly when the Pacific is warmer (El Niño), although there is no significant difference in either the total number of stations with changes or those reporting increased rainfall. 

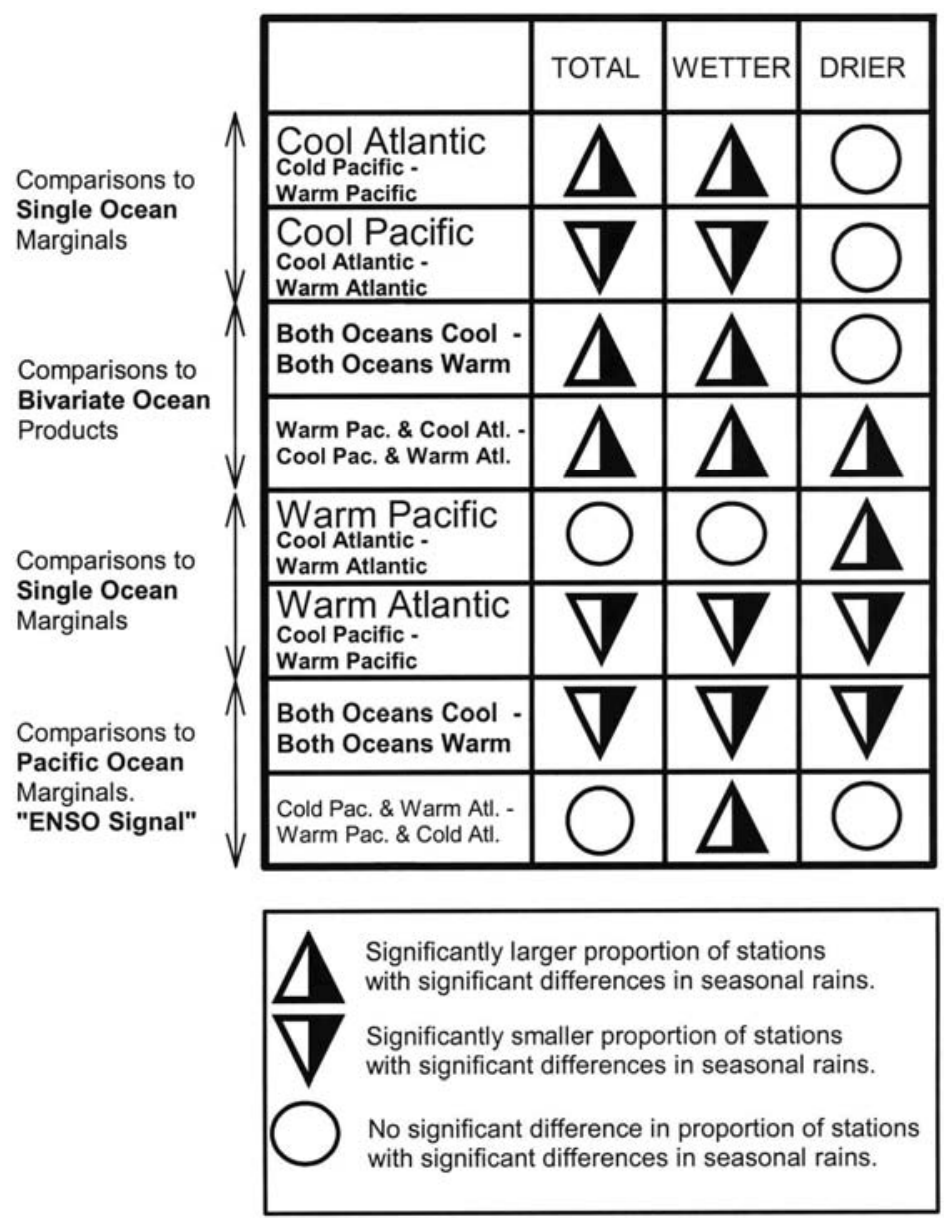

Figure 7. A summary of the results of the test of the proportions of stations recording significant changes in seasonal rainfall totals in comparison to the proportions expected under conditions of rainfall being independent of an interaction with both the SST anomalies in the Pacific and Atlantic. Triangles imply an amplification of the regional response and inverted triangles suggest a reduction in the regional response.

The results summarized in lines 3 and 4 indicate that the observed proportion of stations experiencing differences in rainfall under the prescribed oceanic conditions are are greater than would be expected if rainfall was independent of the interaction between SST in both oceans. The only exception to this is the lack of a significant change in the proportion of stations reporting drier conditions when comparing both oceans being cool to both being warm.

Given the previously noted influence of ENSO in the region, it may be of more practical interest to investigate whether comparisons 3 and 4 statistically strengthen or weak- 
en the regional signal of ENSO ((cool Pacific - warm Pacific). Line 7 indicates that a significantly smaller proportion of stations show differences in precipitation (wetter and/or drier) when both oceans are cooler compared to when both are warmer, than observed when a comparison is made between a cool Pacific ( $\sim$ La Niña) and a warm Pacific ( El Niño), suggesting that an SST anomaly of the same sign in the Atlantic mollifies the ENSO signal. Line 8 indicates that a greater proportion of stations experience increased precipitation as a result of the ENSO signal when the Atlantic anomaly is of the opposing sign, implying a slight amplification of the signal.

\section{Conclusions}

These results confirm documented regional effect of ENSO upon precipitation during the Veranillos/Caniculas, which is statistically significant at half of the stations in this region. A geographic division between wet/dry responses is associated with the topographic divide. A lesser, but potentially important, control exerted by SST anomalies in the North Atlantic (23\% of stations) is also present. Broadly speaking, this season is one of intensified trade winds, bringing rainfall to the Caribbean coast and dryness to the Pacific. However the actual physical mechanisms may be more complex than a simple rainshadow effect (Magaña et al., 1999). Waylen et al. (1996) noted that this pattern was enhanced during warm phases of ENSO and diminished during cold phases.

There is no evidence of a contemporary statistical association between the SSTanomalies in the two oceans, but there is ample evidence that seasonal precipitation is dependent upon the simultaneous interaction of both anomalies. The drought, which typifies the Pacific slope during years of warm phase ENSO, is less severe when the Atlantic is warmer, but the reduction in rainfalls may spread over the entire country. Likewise, the pattern of excessive rains on the Pacific slope and droughts on the Atlantic slope, which are normally associated with cold phases of ENSO, weakens during periods of a cooler Atlantic. Cooler temperatures in the tropical Atlantic signify a strengthening of the North Atlantic anticyclone and the associated alisos. When combined with warmer than usual temperatures (lower atmospheric pressures) in the eastern equatorial Pacific the pressure gradient across the isthmus increases and the orographic effects of the Cordillera are emphasized. When the Atlantic is warmer, the resultant reduction in the strength of the alisios reduces rainfall over most of the country. During cold phase of ENSO higher atmospheric pressures occur in the eastern equatorial Pacific, reducing the pressure gradient across the isthmus and reducing the rainshadow effect along the Pacific coast. This pattern is further enhanced with a warmer than normal temperature (lower pressure) in the North Atlantic.

The interaction of the temperature, pressure and wind fields in both oceanic basins therefore appears to have a significant effect upon the seasonal precipitation totals, which appear to be subject to considerable interannual variability throughout the country, not solely the starting date of the rainy season. The dominant scale of interannual variability in the North Atlantic is widely reported as being decadal (Enfield and Alfaro, 1999; 
Enfield et al., 2001; Goldenberg et al., 2001; Latif 2001), while that of the equatorial Pacific is the typical ENSO signal of 3-7 years. The low frequency oscillation of the North Atlantic in combination with the interactive effects outlined here may be responsible for the observed inconsistency in the regional response to ENSO (Ropelewski and Halpert, 1987). The role of topography is crucial in producing the observed patterns and may not be identifiable from data extracted at larger spatial scales. As this "mid-summer drought" is felt regionally from southern Mexico to Panama, it is possible that these observations may have greater regional importance.

\section{Acknowledgements}

This research was supported in part by a grant, ISPIII-022 from the Inter-American Institute for Global Change.

\section{References}

Burt, J.E. and Barber, G.M. (1996). Elementary Statistics for Geographers, Guilford Publications, 640pp., New York.

Conover, W.J. (1980). Practical Nonparametric Statistics, Wiley, New York.

Enfield, D.B. and Alfaro, E.J. (1999). The Dependence of Caribbean Rainfall on the Interaction of the Tropical Atlantic and Pacific Oceans. Journal of Climate, 12: 2093-2103.

Enfield, D.B., Mestas Núñez, A.M. and Trimble, P.J. (2001). The Atlantic Multidecadal Oscillation and its Relation to Rainfall and River Flows in the Continental U.S. Geophysical Research Letters, 28: 2077-2080.

George, R.K., Waylen, P. and Laporte, S. (1998). Interannual Variability of Annual Streamflow and the Southern Oscillation in Costa Rica. Hydrological Sciences Journal, 43: 409-424.

Giannini, A., Kushnir, Y. and Cane, M.A. (2000). Interannual Variability of Caribbean Rainfall, ENSO and the Atlantic Ocean. Journal of Climate, 13: 297-311.

Goldenberg, S.B., Landsea, C.W., Mestas-Núñez, A.M. and Gray, W.M. (2001). The Recent Increase in Atlantic Hurricane Activity: Causes and Implications. Science, 293: 474-479.

Hastenrath, S. (1967). Rainfall Distribution and Regime in Central America. Archiv fur Meteorologie, Geophysik, und Bioclimatologie, Serie B., 15: 201-241.

Hastenrath, S. (1976). Variations in low-altitude Circulation and Extreme Events in the Tropical Americas. Journal of Atmospheric Sciences, 25: 2222-2231.

Latif, M. (2001). Tropical Pacific/Atlantic Ocean Interactions at Multi-Decadal Time Scales. Geophysical Research Letters, 28: 539-542

Magaña, V., Amador, J.A. and Medina, S. (1999). The Midsummer Drought over Mexico and Central America. Journal of Climate, 12: 1577-1588.

Ministerio de Recursos Naturales, Energía y Minas (1988). Instituto Meteorológico Nacional Año del Centenario, 1888-1988: Catastro de las Series de Precipitaciones Medidas en Costa Rica. San José, Costa Rica. 
Ropelewski, C.F. and Halpert, M.S. (1987). Global and Regional Precipitation Patterns Associated with the El NiñolSouthern Oscillation. Monthly Weather Review, 115: 1606-1626.

Waylen P.R., Caviedes, C.N. and Quesada, M.E., (1996). Interannual Variability of Monthly Precipitation in Costa Rica. Journal of Climate, 9: 2606-2613.

Waylen P.R. and Laporte, S. (1999). Flooding and the El Niño-Southern Oscillation Phenomenon along the Pacific Coast of Costa Rica. Hydrological Processes, 13: 2623-2638. 